\title{
ANDRÉA FRANÇA \\ Serras da Desordem e 500 Almas: resíduos de rostos, de gestos
}

Resumo:

A partir do documentário Serras da Desordem, de Andrea Tonacci, discute-se o espectro da objetividade e da verdade da representação nas imagens documentais e o lugar do espectador na construção destas imagens; discute-se a auto-representação indígena no Projeto Vídeo nas Aldeias e a produção de uma subjetividade indígena no documentário 500 Almas, de Joel Pizzini.

Palavras-chave: documentário; vídeo; subjetividade

Abstract:

Andrea Tonacci's Serras da Desordem, Joel Pizzini's 500 Almas and the work of the Video nas Aldeias Project allow us to approach the production of an indigenous subjectivity in documentary movies and to address the shadow of objectivity and truth in documentary movies, as well as the role of the spectator in these images.

Key-words: documentary; video; subjectivity 
ndrea Tonacci, em Serras da Desordem (2006), reencena, refaz, reconstitui a trajetória
errante de um índio de etnia guajá, chamado Carapiru, sobrevivente de um massacre de
fazendeiros que aniquilou toda sua aldeia em 1978, no interior do estado do Maranhão. O índio escapa e passa a perambular pelo Brasil adentro até ser acolhido, dez anos depois, por uma família de camponeses no interior da Bahia, a uma distância de mais de dois mil quilômetros da aldeia incendiada. Tempos depois, o sertanista Sydnei Possuelo fica a par da situação e faz as primeiras tentativas de aproximação com o índio. Levado finalmente a Brasília, é identificado como um remanescente da tribo Guajá, sendo que a confirmação é feita por um jovem índio intérprete, da mesma etnia, resgatado também há mais de dez anos pela Funai. No encontro dos dois, a surpresa: eles se reconhecem como o pai e o filho que ambos julgavam assassinados durante o massacre da aldeia.

Se essa história fosse inventada por um roteirista, seja de cinema ou de televisão, diríamos que é excessivamente melodramática, sensacionalista e nada provável. De fato, na época em que se promoveu o encontro de Carapiru com o jovem índio intérprete, o programa Globo Repórter da Rede Globo de Televisão registrou a cena, relatando em cadeia nacional o ocorrido e destacando especialmente sua dimensão fantástica e inusitada: a longa e solitária errância do índio, o reencontro inesperado com o filho dez anos depois, a "volta" para a aldeia como o final do périplo, etc. Serras da Desordem, porém, se interessa menos pelo reencontro em si, embora o mesmo esteja lá, presente nestas imagens de arquivo de 1988, e mais pelo que ocorreu longe das câmeras televisivas, discreta e silenciosamente, antes e depois do encontro.

Mas não é só. Para além desse diálogo crítico com as imagens do telejornalismo, na sua espetacularização da pobreza e de grupos sociais marginalizados, o filme de Tonacci também nos retira do lugar da crença nas imagens do cinema documentário, lugar historicamente construído por uma rede de discursos - de diretores, produtores, seus filmes, os espaços de exibição, as associações, as publicações especializadas, a crítica - cuja tradição retórica enfatiza seu caráter de sobriedade na relação com o outro, de verdade da representação, de testemunho do que o mundo é. Serras da Desordem nos retira deste lugar ao misturar imagens de reconstituição, arquivo, entrevistas, observação, interação entre diretor e personagem, instilando a dúvida no espectador e colocando em xeque o lugar confortável ao qual está habituado diante das imagens midiáticas cotidianas (a identificação fácil do que é verdadeiro e do que é falso). 
Neste artigo, faço um diálogo do filme de Tonacci com o "filme-origem" do cinema documentário, Nanook, o esquimó, e a representação do outro exótico e distante; em seguida, uma aproximação de Serras da Desordem com os vídeos dos realizadores indígenas do Projeto Vídeo nas Aldeias e a auto-representação no documentário e, por fim, um diálogo, por contraste, de Serras da Desordem com o documentário 500 Almas (2004) de Joel Pizzini.

O início de Serras da Desordem mostra um índio sozinho na floresta, preparando uma fogueira. O tempo da cena é longo, pois trata-se de mostrar uma operação lenta, silenciosa, um saber erigido e conservado em função de práticas e discursos de um grupo. Nos trinta minutos iniciais, vemos a aldeia, os índios nas redes, as crianças brincando e outras atividades que se desenrolam "independente" da câmera; a mise-en-scène revela a cumplicidade do cineasta com o grupo, o não constrangimento em participar do jogo teatral que é proposto, a dimensão lúdica da encenação coletiva. Cinema de observação e mise-en-scène que remete imediatamente à "origem" do documentário com o clássico Nanook, o esquimó, filme de Robert Flaherty (1922).

Em Nanook, também encontramos o interesse em captar a vida, os hábitos e as tradições, o embate com a natureza de onde se extrai um saber e um fazer e, ainda, o longo e intenso contato do cineasta com o grupo filmado. Mas em Flaherty, as cartelas explicativas situam o espectador logo nos primeiros minutos - a luta pela sobrevivência dos esquimós em meio à neve torrencial e ao frio cotidiano - enquanto em Tonacci, há o desconforto de não ser possível julgar o que se vê (reconstituição, observação, encenação?).

De fato, a história do cinema documentário mostra que este campo sempre se defrontou com o espectro da objetividade, da verdade da representação, da transparência, de modo que o lugar do espectador destas imagens pudesse ser o lugar estável daquele que aceita e acredita no mundo do filme como real. Desde suas origens, com Robert Flaherty mas também com Dziga Vertov (O homem com a câmera, de 1929), o pensamento e a reflexão sobre o campo do documentário não parou mais de se debater entre as noções de verdade e mentira, autenticidade e ficção, realidade e mise-en-scène. Basta atentarmos paras as inúmeras expressões que pretenderam dar conta de suas diferentes modalidades, metodologias e procedimentos ao longo da história, tais como "cinema-olho", "cinema do vivido", "cinema-verdade", "cinema-direto", etc. O que se depreende deste conjunto de expressões é o modo como se forjou historica e socialmente o lugar do espectador neste cinema, a forma requerida de se colocar diante de um filme documentário, desde sua origem, a crença encorajada como um critério diferenciador em meio às imagens do cinema de ficção, de animação, das telenovelas. 
Teóricos, críticos e cineastas vão afirmar que o espectador que vê um documentário não é o mesmo quando vê um filme de ficção. Trata-se de um outro olhar. Existem exigências, expectativas de adequação da imagem ao mundo, um juízo a respeito do diretor e da sua obra que marcam essa diferença radicalmente. É claro que os cinemas modernos dos anos 60, sobretudo os filmes de Jean Rouch, inauguram toda uma problematização a respeito das imagens do mundo, da possibilidade de falar do outro, da dinâmica das subjetividades em jogo (do realizador e do personagem), questionando a posição privilegiada do diretor como produtor exclusivo de sentido e o lugar estável do espectador de documentários que por hábito histórico, social, cultural, estético, acostumou-se a acreditar sem duvidar daquilo que vê.

Nos documentário modernos, o que sobressai é o real que escapa às narrativas já formadas e que nos captura sob a forma do acaso, do silêncio, da surpresa, do acidente (filmes como Jaguar, de Jean Rouch, Crônica de um verão, de Jean Rouch e Edgar Morin, Dont't look back, de D. A Pennebaker, Caixeiro viajante, dos irmãos Maysles, entre tantos outros). Documentários que supõem uma relação entre cinema e mundo assim como um real problematizados ou, ainda, uma intuição vital capaz de apontar para alguma coisa que não é da ordem do que está dado.

De todo modo, não há neste momento os problemas ligados a um mundo massivamente midiatizado, um mundo do qual a produção audiovisual cotidiana pretende dar conta, comunicando, formando, informando, controlando, dentro de uma lógica onde as formas de relação com o outro caracterizam-se pelo poder de ver e julgar sem contrapartida. Como enfatiza o crítico e documentarista Jean-Louis Comolli, o que está em jogo hoje é a satisfação dos prazeres voyeuristas e do desejo de ver e saber sempre mais. ${ }^{1}$

Serras da Desordem é um documentário que chacoalha o espectador do lugar habitual diante da produção audiovisual. O filme trava um embate com esta produção à medida que cada imagem ativa simultaneamente no espectador a dúvida e a crença, o distanciamento e a identificação, a impressão de realidade e o artifício. ${ }^{2}$ Se o mundo das imagens midiáticas nos parece frequentemente dado por graça divina e desprovido de ambigüidades, o mundo em Serras da Desordem se mostra como fruto de escolhas, articulações, elipses, reticências; Tonacci instila mais dúvidas do que certezas. Afinal, não há

${ }^{1}$ COMOLLI, Jean-Louis. Voir et Pouvoir - l'innocence perdue: cinéma, télévision, fiction, documentaire. Paris: ed. Verdier, 2004, p. 214

2 Como também Juízo (Maria Augusta Ramos, 2008), Jogo de cena (Eduardo Coutinho, 2008) e Santiago (João Moreira Salles, 2007) que mereceriam um estudo dentro desta discussão. Ver também o artigo “O cinema, seu duplo e o tribunal", da autora, na Revista Famecos: mídia, cultura e tecnologia n. 36, 2008. 
legendas para as falas de Carapiru e muitas das nossas perguntas, ao término do filme, continuam sem respostas: por que o índio não aprendeu a falar português? Como foi possível viver durante dez anos errando solitário pelo interior do país? O que ele sentiu? E depois, como foi ser acolhido por uma família de camponeses? O que significou emocionalmente o reencontro com o filho? E a volta para a aldeia, depois de tanto tempo vivendo com o homem branco, foi bom? Para nenhuma destas perguntas há respostas. O que existe é a experiência radical do silêncio, da voz que não comunica e da opacidade do corpo indígena.

E, no entanto, o filme de Tonacci é uma história que é revivida pelo próprio índio, com a ajuda dos sertanistas e camponeses que também reencenam várias situações, além de darem depoimentos e interagirem com a câmera. Há também uma montagem que trabalha no sentido de refazer e reorganizar o sentido de fotografias, imagens de arquivo de natureza diversa e material oriundo do jornalismo impresso da época; todo esse material, de fontes e suportes diversos, ${ }^{3}$ é explorado de modo a mostrar uma empreitada que começa no paraíso idílico e mítico da aldeia, passando pela chegada da civilização branca - representada por uma longa seqüência de imagens-genéricas tais como a "entrada" do trem, dos grileiros, o desmatamento selvagem, a expropriação da terra, a construção da transamazônica, a ditadura militar, a Copa do Mundo - até o isolamento de Carapiru, seja como andarilho pelo interior do país, seja como sobrevivente no interior da reserva indígena no Maranhão.

Se no clássico Nanook, o esquimó, a montagem é simplesmente encarregada de conservar os planos mais reveladores, de organizar sua alternância para condensar a espera, de regular sua sucessão para veicular o interesse dramático, em Serras da Desordem, a montagem tem um papel polifônico, pois não só exibe seu artifício como mostra que, na relação entre cinema e mundo, há definitivamente uma mudança de natureza face a qual a câmera tem sua responsabilidade. Em Nanook, há o projeto de filmar a natureza como a verdadeira paisagem do homem, longe das maquiagens e dos estereótipos do estúdio; Flaherty faz seus personagens reencenarem diante de si aquilo que resta das cenas dos homens primitivos, a luta simples e nobre dos "bons selvagens" pela sobrevivência, diante da qual a câmera deve funcionar como um capturador das forças da natureza e a montagem como capaz de fazer a dramatização deste embate.

Serras da Desordem, ao contrário, não pretende nos tornar próximos do distante; seu humanismo não pretende restituir o natural eliminando o artificial, tampouco nos aproximar da natureza selvagem, da família tribal, das tradições. O que existe, dentro deste diálogo com o filme-

\footnotetext{
${ }^{3}$ Como o filme é resultado de uma longa pesquisa, que começa em 1993 durante uma conversa com Sydnei Possuelo até as primeiras gravações em 2000, os suportes de captura variam muito.
} 
origem do cinema documentário, é a negação absoluta de um estado de natureza bruto, intocado, pois este estado seria também um mito criado pelo homem branco civilizado para uso próprio. “Nesse filme, faço a minha leitura: a visão de que nem mesmo a história dele [Carapiru] lhe pertence mais, já faz parte de uma narrativa mais ampla, historicista, subjetiva, pessoal, nossa", afirma Tonacci. ${ }^{4}$ E o final é elucidativo deste pensamento: vemos a mesma cena inicial, em que Carapiru prepara demoradamente o fogo, só que agora Andrea Tonacci aparece dentro do quadro, orientando e dirigindo o índio.

A auto-representação indígena no cinema documentário

Podemos fazer, nesta perspectiva, uma aproximação de Serras da Desordem com os vídeos dos realizadores indígenas, do Projeto Vídeo nas Aldeias, coordenado por Vincent Carelli e Mari Corrêa. Para além do pioneirismo, este projeto, que existe desde os anos 80, apresenta não apenas a produção de vídeos da equipe do projeto sobre os índios no Brasil, como também vem formando uma geração de realizadores indígenas que trabalha a partir de uma espécie de auto-etnografia, auto-representação ou auto-documentário, em que os próprios índios pesquisam, discutem, registram e editam suas imagens, passando de objetos do discurso a sujeitos. ${ }^{5}$

Como em Tonacci, existe a preocupação dos coordenadores de colocar essas culturas no eterno presente das imagens e da narrativa audiovisual, sendo que o desafio é, neste Projeto, fazer do vídeo um instrumento de reconfiguração de forças e de produção de sentido e interpretação do mundo. Ao retirar a câmera da mão dos antropólogos e cineastas profissionais e formar realizadores indígenas, a primeira questão que surge lancinante é a do deslocamento de poder-saber, isto é, de um desvio decisivo na produção e na circulação de conhecimento. Quem tem a câmera tem o comando e a simples posse pelos índios deste instrumento de observação, registro, intervenção, captura, pode produzir um outro pensamento, uma outra lógica do olhar, dando visibilidade a outros modos de sentir.

\footnotetext{
${ }^{4}$ Entrevista com o diretor, no livro Serras da Desordem (org. Daniel Caetano). Rio de Janeiro: Azougue Editorial, 2008, p. 104

${ }^{5}$ Ver, a respeito deste Projeto, particularmente os ensaios "A livre afirmação dos corpos como condição do cinema", de Andréa França, no Catálogo da Mostra Vídeo nas Aldeias - um olhar indígena, ano de 2006, e "Câmera muy very good pra mim trabalhar", de Ivana Bentes, no primeiro Catálogo da Mostra Vídeo nas Aldeias - um olhar indígena, de 2004.
} 
Nesses vídeos, para além da relação entre os próprios índios, somos nós que nos vemos como alteridade. Vemos uma história que pensamos conhecer - à medida que são histórias que se referem ao Brasil e que apontam para aquilo que nos unifica bem como o que nos distingue -, mas contada em outros termos, onde a fala do outro, sua lógica e a construção das imagens nos obrigam constantemente a nos reposicionar. Assistindo a Shomotsi (2001), Kiarãsã Yõ Sãti: o amendoim da cotia (2005), Kinja Iakaha: um dia na aldeia (2004), Daritidzé: aprendiz de curador (2003), Das crianças Ikpeng para o mundo (2002), todos realizados por videastas índios, o que mais surpreende, é perceber que essas imagens jogam em duas frentes, dirigem-se a dois tipos de público bastante distintos: para o homem branco, ocidental, esses documentários parecem nos dizer que somos nós que nos tornamos outros, "índios", pois os que foram esquecidos não esqueceram; e para os índios, os vídeos não só permitem que eles tenham acesso, elaborem e recriem a sua própria imagem, como também mostram que eles podem ensinar coisas que outras comunidades indígenas, assim como o homem branco, não sabem.

E, o que essas imagens do "outro" indígena - bem longe de nós, brancos - têm, por que elas conseguem nos falar, dirigir-se a nós, fazer-se compreender e, mais do que isso, como é possível que elas nos façam perceber nossas maneiras de ser, de nos pensar, como é possível que elas nos falem do nosso mundo? Primeiramente, as histórias que estes filmes contam são aquelas da descoberta por nós de toda uma estratégia lúdica e fabulatória dos índios que jamais tínhamos visto sob esse ângulo. Surpreende a diversidade de rostos, as formas de representar o espaço e o tempo das aldeias, de se apropriar da imagem, de solicitar o espectador. Muitas vezes, os índios entram em cena para "encenar" o que acreditam que seja bom para eles. Desse modo, existe sempre a possibilidade de alguém tomar a cena para fazer a "sua" performance, o "seu" filme.

É claro que a intimidade e a cumplicidade entre aquele que filma e aqueles que são filmados favorece, e muito, essa afirmação dos corpos em cena que está patente em todos os planos de cada um desses documentários. Mas, para além disso, existe um desejo de filme que não está somente do lado dos índios videastas, mas do outro lado da câmera também: há um desejo de filme tão grande quanto o desejo daquele que filma e, ao tornar esse desejo visível, atuante, falante, essas imagens criam um cinema absolutamente igualitário, um cinema onde cada corpo - seja ele da planta, da concha, do jacaré, da criança, do velho - tem o mesmo valor que um outro para a câmera: todos eles são igualmente diferentes, igualmente importantes e únicos. É claro que o grande desafio, neste Projeto, é fazer do vídeo um instrumento de reconfiguração de forças, rearranjando compreensão, explicação, leitura do mundo, onde para além da relação entre os próprios índios, nós mesmos podemos nos ver como alteridade. 
Em Das Crianças Ikpeng para o Mundo (2002), quatro crianças apresentam sua aldeia, sua comida, seu cacique, e convidam o espectador - que, para elas, serão outras crianças índias, como elas - a fazer o mesmo, interrogando-o, solicitando-o. A força do dispositivo montado aqui é que primeiramente essas imagens são concebidas como uma espécie de vídeo-carta, em que se o "remetente" são as crianças da aldeia Ikpeng, o "destinatário" poderá ser qualquer um que tenha interesse - cinematográfico, antropológico, etnográfico - ou curiosidade pelas histórias dos outros. "Todo documentário se interessa pela ficção dos outros", disse Jean-Luc Godard, sintetizando em larga medida a proposta destes filmes. O destinatário se bifurca então entre um destinatário próximo as crianças e os índios de outras aldeias - e um destinatário distante, um outro sempre outro como nós mesmos. Em segundo lugar, trata-se de um documentário que soube encontrar as crianças certas, e que fez da arte do encontro uma possibilidade de que a prática documentária pudesse ser de fato compartilhada, "tomada" pela pessoa filmada.

Se os olhares das crianças para a câmera - seus gestos, suas expressões, seus sorrisos, suas falas - são momentos bonitos, fortes, intensos, é porque eles mostram a consciência de que se trata de um jogo entre quem filma e quem é filmado, um jogo em que a performance dos índios está ligada a fatores que são produzidos pelo documentário, para o documentário e que não existiriam sem ele. Em Um dia na Aldeia (2004), filme que detalha o cotidiano da aldeia Cacau, na Amazônia, um grupo de índias volta da colheita de wesi ("os brancos falam açaí"), com seus bebês acoplados ao corpo enquanto caminham e, de repente, ouvimos uma delas: "estão falando de mim? Todas somos muito bonitas. Eu não sou gorda não, vou emagrecer". E todas riem muito.

Há também vídeos que tratam do cotidiano das aldeias. O dia a dia numa temporalidade lenta, outra, sem festejos ou rituais. Shomõtsi, do realizador índio Valdete Pinhanta, é uma pérola na forma como captura o lento fluxo do tempo cotidiano do seu próprio tio Shomõtsi, escolhido como personagem de uma crônica da aldeia, na fronteira do Brasil com o Peru. O vídeo é inteiramente narrado pelo sobrinho, realizador do trabalho, em voz over, misturando a fala com os ruídos ambientes, a música local, os sons da mata, do rio, a conversa do tio com outros índios e com o próprio cinegrafista e sobrinho: "faz careta para a câmera", "sorria, o buraco da filmadora está vendo", "não filma o meu saco".

Nestes vídeos, a proposta de exprimir uma identidade já dada ou uma realidade estanque que pré-existiria ao filme, tão presente no discurso antropológico, etnográfico ou nos documentários expositivos clássicos, não tem lugar, pois a realidade nasce junto com a realização do filme, na relação 
dos dois. Em $O$ amendoim da cotia, o chefe da aldeia Panará simula, para os índios que estão à sua volta, estar transando com uma bananeira como se esta fosse uma índia; ele mexe o corpo, rebola, agarra a planta, descreve a chegada do gozo enquanto, em volta dele, as índias o observam, interrompem a colheita do amendoim e dão boas risadas.

Por que afinal estas imagens nos falam deles e de nós? Certamente não é apenas porque o espectador tem a possibilidade de avaliar igualmente cada personagem, seus gestos, suas histórias, sua entrada em cena; embora o cinema seja aqui uma experiência compartilhada e de afirmação de cada ser, isso simplesmente não basta para que o "nós" transforme-se em uma instância problemática. O que ressignifica o jogo de posicionamentos entre "nós" e "eles" é a existência freqüente de uma platéia na cena do filme que ri, comenta, brinca, faz piadas - índios, índias, crianças e velhos -, enfim, que reage às performances e às situações representadas para a câmera, como nós. É esta platéia que faz funcionar um jogo de espelhos a refletir dois públicos distintos - o homem branco e o indígena “todos os dois ocupando simultaneamente a posição de espectador". ${ }^{6}$

Público, como nós, o índio produz uma espécie de rebatimento em espelho do espectador de cinema. Público, como nós, o índio turva a transparência do que seria vivido como "comum", nos apontando o dedo em riste e nos chacoalhando para nossa própria diferença. No Projeto Vídeo nas Aldeias cada ser e cada corpo solicitam de nós uma comunhão paradoxal porque acentuam a singularidade de uma comunidade de diferentes, reiterando que a nação imaginada é um processo frágil, pátria desconhecida nos seus modos de manifestação.

\section{As 500 almas de Carapiru}

Serras da Desordem e 500 almas (2004, Joel Pizzini) documentam povos em ruína, restos de povos, vestígios de civilização. Em Tonacci, temos um índio errante, sem memória, sem tribo, sem voz, sem aldeia; em Pizzini, temos a aldeia, as vozes, a memória dos gestos, mas não existe o índio. Resíduos do índio, resíduos da aldeia. A memória da dor, em ambos, perfaz a própria “origem” do Brasil. Memória local/nacional que, somada ou empilhada aos discursos midiáticos-globais de outros traumas e sofrimentos históricos (Holocausto, Bósnia, etc), disputa um lugar muito distante do monumento ou memorial.

\footnotetext{
${ }^{6}$ Esse aspecto da platéia no interior da cena, presente em vários destes vídeos, é analisado no ensaio de minha autoria citado acima, "A livre afirmação dos corpos como condição do cinema".
} 
Estes filmes falam de uma memória que se insinua como vestígio, permitindo continuamente novas perspectivas daquilo que é mostrado e afirmando a vitalidade destas falhas por onde escoam modos de vida fora da representação. E ambos nos legam a questão: como converter em experiência o silêncio de povos que viveram um acontecimento inumano, seja o incêndio criminoso que dizima toda uma aldeia (os guajás de Tonacci), seja a declaração oficial de povo extinto (os guatós de Pizzini)? Qual é a natureza e o que podem estes discursos da memória que criam uma radical defasagem entre os personagens e o espectro das identidades étnicas e culturais que os recobrem frequentemente? Que lugar político e que nicho de mercado estes filmes ocupam em meio aos muitos outros discursos memoriais midiatizados que, ao contrário, instrumentalizam os mesmos personagens com vistas à produção "transparente" de realidade?

Serras da Desordem recria a história do índio Carapiru como ficção a partir das várias evidências discursivas - depoimento de sertanejos, indigenistas, fotografias, arquivos audiovisuais e impressos. Todos os primeiros 25 minutos do filme funcionam como um prólogo que perfaz a história do Brasil sob a perspectiva genérica-desenvolvimentista: as primeiras imagens mostram um mundo idílico, onde a aldeia indígena flutua espectral acima do tempo histórico em uma espécie de paraíso não contaminado pela civilização. Em seguida, a chegada da civilização, exibida na seqüência das imagens documentais de arquivo até a imprevista e inusitada inserção das imagens do ator Paulo César Pereio, do filme Iracema - uma transa amazônica. Tonacci provoca um recuo irônico face aos discursos eloqüentes da memória oficial/monumental, de modo a mostrar que as grandes narrativas têm falhas, arestas, rusgas e que também são ficções da memória histórica.

De uma narrativa teleológica e caricata que exibe o que seriam os grandes feitos do povo brasileiro, do país, dos homens trabalhadores, passamos para uma história singular que mostra que o sentido da dor não decorre de uma entidade genérica - os povos, as nações - mas de sujeitos singulares que viveram de dentro a barbárie. Trata-se, a partir da entrada em cena de Carapiru, de realizar uma escrita da dor e da morte sobre um corpo sem história. Resíduos do índio.

Em 500 almas, poetas, antropólogos, historiadores, cineastas lutam, assim como os descendentes dos índios guatós do Pantanal do Mato Grosso, para restabelecer a identidade guató. Tais índios foram declarados oficialmente extintos nos anos 60, resistindo de maneira dispersa, anônima, vivendo sob o disfarce de população ribeirinha como estratégia de sobrevivência. O filme mostra o esforço desses indivíduos dispersos para reconstruírem a memória dessa origem. Joel Pizzini explora poeticamente a tensão entre o tempo linear da memória histórica - presente nas declarações 
dos lingüistas, dos historiadores, dos guatós ou daqueles que se dizem guatós - e o tempo múltiplo e facetado de uma "eternidade que passa", expresso na permanência solene da natureza, do som da viola-de-cocho, de objetos guardados no Museu Antropológico de Berlim, enfim, da memória e do imaginário da aldeia guató.

Logo na primeira cena, ouvimos sons e vozes em alemão, na língua guató, em português, produzindo uma espécie de ruído indiscriminado a sugerir uma língua outra, ainda murmurante, como diz o poeta Manoel de Barros. "Acho guató uma palavra linda. Eu comecei a me simpatizar por esse negócio de guató por causa da palavra propriamente dita." Essas vozes sem corpo, espectrais, sem referências espaciais ou mesmo temporais, perambulam junto com o movimento da câmera sobre as montanhas, a mata, o rio. Somente aos poucos, elas se encarnam nos corpos e ganham consistência nas imagens. 700 almas mostra a permanência flutuante e plural da memória guató, do imaginário da aldeia que, desencarnado do corpo indígena, quer encontrar o índio, quer dar-lhe visibilidade, de modo a recuperar no corpo a memória e a luta enunciada nas vozes. Como se cada personagem do documentário fosse uma testemunha sem fala mas com voz. Resíduos da aldeia.

O que é visto, em 500 Almas, sobre o cotidiano desta gente ribeirinha - a construção da canoa, a fabricação da viola, o trançado das palhas, e os (re)encontros entre os personagens - nos remete ao filme original do cinema documentário, o clássico Nanook,o esquimó, já discutido aqui em suas ressonâncias com Serras da Desordem. Como no filme de Flaherty, as imagens de ofícios em extinção remetem a uma "sabedoria ancestral", sublinhada ainda mais através dos longos planos, dos tempos mortos, do ritmo silencioso das canoas que se assemelha ao início de Louisiana story (1948), outro filme de Robert Flaherty.

E como capturar histórias desencarnadas do corpo (dos guatós) ou o silêncio dos silenciados (os guajás)? Tonacci e Pizzini inventam, cada um a seu modo, procedimentos para dar conta dessa experiência traumática. Como se tais vidas "residuais" só pudessem comparecer na linguagem sob a condição de instalarem um vazio central, uma lacuna, que este retorno pelo cinema deve exibir, pois entre a história dos índios e a linguagem nos deparamos com a desnaturalização das diferenças e da história.

Em Tonacci, o trajeto do índio é encenado, construído, assim como a performance dos grileiros, o encontro com a família de camponeses, com os indigenistas, a volta à aldeia e a sua

\footnotetext{
7 Para uma análise mais extensa e rica do filme, ver o artigo de Angeluccia Habert, "Intersecção entre forma e informação: um filme etnopoético", na ALCEU: revista de comunicação, cultura e política n॰16, 2007.
} 
permanência nela. Existe uma tensão entre presente e passado, arte e vida, experiência e memória, que é dramatizada. Em Pizzini, é o sentimento de ser índio que está em cena, um sentimento que é suposto como fixo, permanente e, em 500 Almas, é apresentado como um processo dinâmico, de auto-produção fabuladora. Ser índio é curiosamente um modo de criar uma identidade assim como um critério para erigir diferenças (vários personagens dizem que são índios), criando laços de pertencimento e marcando um posicionamento dos sujeitos no terreno do dizer. E identidades são modos de posicionamento, como destaca Stuart Hall, são "pontos instáveis de identificação ou sutura, feitos no interior dos discursos, da cultura e da história. Não é uma essência, mas um posicionamento" ${ }^{8}$ E posicionar-se é estabelecer um lugar, uma posição, a partir de parâmetros externos de referência. Se a identidade tem a ver com práticas, discursos, objetos que nos posicionam no mundo, isto é, que dizem nosso lugar com relação ao outro, os personagens de 500 Almas marcam e estabelecem uma posição através do lugar que constroem ao se dizerem "índios".

E se dizer "índio", em 500 Almas, é uma estratégia de sobrevivência e não simplesmente uma questão étnica. Trata-se de uma escolha. Assim é que um personagem pode dizer: "Nasci e me criei aliado dos guatós, também deverei ser considerado guató". Como se o movimento de recuperação da memória - imprecisa, residual - fosse uma defesa contra as formas contemporâneas de exclusão: o homem comum não quer ser "qualquer um" - pobre, miserável, invisível -, ele quer ser índio. Podemos então concordar com Hall, na esteira de Foucault, quando diz que a identidade pergunta menos "o que nós somos" (essência) e mais "o que nos tornamos" (processo).

A memória (pessoal, histórica, nacional) não é uma questão de acumulação de informações, mas uma questão de assimilação e esquecimento, de condensação e deslocamento. Porque sem esse trabalho afetivo de integração de fragmentos e também coletivo, público, de objetivação da história, com seus pontos cegos e suas descobertas, não pode haver atualização do sabido no vivido e viceversa. É esse trabalho de reapropriação do tempo que é tema de tantos documentários de realizadores os mais diversos como Eduardo Coutinho, Cao Guimarães, Joel Pizzini, João Moreira Salles, Eduardo Escorel, Sandra Kogut, Lucas Bambozzi, Arthur Omar, etc. Diretores que estão longe de acreditar na permanência do passado em imagens cheias de nostalgia, compaixão ou indignação. O que vemos aqui é a permanência da memória como algo sempre por vir, o uso de imagens que se tensionam e que colocam em xeque nossa maneira de as "legendar".

\footnotetext{
${ }^{8}$ Hall, Stuart. Identidades culturais na pós-modernidade. Rio de Janeiro: DP\&A, 1997, p. 70.
} 
Porque finalmente os riscos estão aí desde sempre: riscos de confusão entre lembrança e história, entre passado e imagens do passado, entre as narrativas da nação e a experiência singular de exclusão, desigualdade, discriminação. E o cinema - por ser uma mídia que se desenrola não só na tela da sala mas sobre a tela mental do espectador, por supor que o espectador não está somente diante do filme, mas dentro dele, tomado e desdobrado pela sua duração - tem a potência de produzir novos sentidos, novas terras imaginadas tanto daquilo que poderia ter sido, no passado, como daquilo que deve ser, no presente. O cinema tem a habilidade única de solapar o caráter hegemônico das imagens oficiais e de outros regimes de verdade totalizantes. Como lembra Gilles Deleuze, se a imagem do cinema promove uma pedagogia do olhar é porque é capaz de revelar uma nova camada que está em gestação, uma nova combinação de palavras e coisas que não pode ser lida nos termos de linguagens existentes. O cinema ensina a procurar o que deve estar onde não está ainda.

E os filmes de Tonacci e de Pizzini nos defrontam com esse campo problemático quando colocam em cena narrativas da memória como resíduo, quando permitem continuamente novas perspectivas e novas entradas para aquilo que é mostrado. O desconforto provocado por estas imagens provém das várias lacunas por onde escoam modos de vida que não estão assentados no comum dos discursos, das práticas, das objetivações cotidianas: o que significa um índio sem aldeia e a aldeia sem o índio? O que é mostrado, o que é escondido? Onde estou no olhar destes indígenas? É como se tais filmes nos legassem essas e outras perguntas, tais como: o que é produzir imagens e narrativas de crimes históricos, quais são as estratégias de representação para além dos pares dicotômicos correta e incorreta, vitimizante e culpabilizante?

Questões complexas que conduzem aos modos pelos quais o cinema documentário fabula narrativas sobre memória histórica, seja enquanto monumento - histórias que legitimam os discursos hegemônicos sobre o passado -, seja enquanto fabulação - a história como um campo de dobras, lacunas e descontinuidades. Neste aspecto, Serras da Desordem e 500 Almas são documentários que trabalham o campo da memória histórica enquanto fabulação.

Nos primeiros minutos de 500 Almas, ouvimos vozes humanas superpostas, múltiplas, que se distinguem muito pouco da música e dos ruídos; existem também sons guturais, indeterminados, de línguas faladas que não reconhecemos, até o início de uma discreta distinção das palavras e dos ruídos, embora os significados ainda deslizem, deslocando-se num campo obscuro. Serras da Desordem utiliza indistintamente reconstituição, depoimentos dos envolvidos, imagens de arquivo retiradas de diferentes fontes: do cinema brasileiro, da Companhia mineradora Vale, do Major Thomaz Reis da 
Comissão Rondon, etc. Há um farto material em que se apoiar para fazer uma investigação histórica, mas Tonacci sabe que esta investigação é sempre uma espécie de busca pelo tempo perdido a partir de informações residuais.

O que deixa o espectador de Tonacci em uma posição de desconforto é que o protagonista dessa história seja um "índio desterrado", sem passado, sem aldeia, sem fala. Porque ele tem voz, mas não há partilha, comunicação, seja com os sertanistas, com a equipe do filme, com os próprio índios da aldeia awa-guajá. Como se a vida e os acontecimentos vividos por Carapiru não pudessem jamais ser compreendidos, representados. Trata-se de um corpo inabitável, opaco. Esse vazio, repetido, nos faz pensar nos modos de representar o silêncio daqueles que foram silenciados, nos modos de garantir essa experiência paradoxal de desencontro entre a palavra e o corpo. Se o mais profundo do homem é a pele, como escreveu Paul Valéry, a pele pode ser também uma fronteira inabitável, ainda que o corpo esteja lá. Serras da Desordem mostra que o encontro do corpo do índio com o do homem branco transformou o indígena em um ser desprovido de fala, sem caminho porque, para Carapiru, todos os regressos tornaram-se inabitáveis.

Assim é que sua presença - sorridente, imediata, cordata - parece expor ironicamente o "crime" desta representação, o fosso incontornável entre passado mítico e passado real, entre as imagens que sustentam a narrativa da nação e a irrupção da alteridade dos excluídos. Ao índio de Tonacci, cuja vida foi atravessada pela violência extrema e pela solidão, a ele não foi dada nem mesmo a chance de fabular e inventar um mundo, mesmo que este fosse o pequeno mundo do seu entorno. Ele tem voz, mas está privado da palavra, ao contrário de todos os outros que testemunharam sua passagem. Não há legendas para ele, não há partilha possível. Mas o seu silêncio não é vazio. Ele é somente o lugar de uma experiência - do cinema - impossível de ser transmitida pelas palavras ou pela ausência delas.

Muito diferente do Projeto de auto-representação indígena da Ong Vídeo nas Aldeias, Tonacci não tenciona fazer do filme um instrumento de reconfiguração de forças, de modo a modificar compreensão e leitura do mundo. O corpo opaco do índio apenas exibe a sua face inacessível a nos interpelar e inscreve, na sua ambigüidade cinematográfica, resíduos de gestos, instintos, rostos em vias de desaparição. 
PERIFERIA - Volume 1. Número 1.

Andréa França é doutora em Comunicação e Cultura pela Escola de Comunicação da UFRJ. Professora da graduação e do Programa de Pós-graduação do Departamento de Comunicação da PUC/RJ. Autora de Cinema em Azul, Branco e Vermelho a trilogia de Kieslowski (Sette Letras, 1996), de Terras e fronteiras no Cinema político contemporâneo (Faperj e 7 Letras,

2003); e organizadora, junto com Denilson Lopes, de Cinema, globalização e interculturalidade (ed. Argos, no prelo). É vicepresidente da SOCINE - Sociedade Brasileira de Estudos de Cinema e Audiovisual.

Bibliografia

BENTES, Ivana. “Câmera muy very good pra mim trabalhar", no Catálogo da Mostra Vídeo nas Aldeias - um olhar indígena, 2004.

CAETANO, Daniel (org.) Serras da Desordem. Rio de Janeiro: Azougue editorial, 2008.

COMOLLI, Jean-Louis. Voir et Pouvoir - l'innocence perdue: cinéma, télévision, fiction, documentaire. Paris: ed. Verdier, 2004

FRANÇA, Andréa. "A livre afirmação dos corpos como condição do cinema", Catálogo da Mostra Vídeo nas Aldeias - um olhar indígena, 2006.

FRANÇA, Andréa. “O cinema, seu duplo e o tribunal”, em Revista Famecos: mídia, cultura e tecnologia n. 36, Programa de PósGraduação em Comunicação Social da Faculdade de Comunicação Social da PUCRS, agosto de 2008.

HABERT, Angeluccia. "Intersecção entre forma e informação: um filme etnopoético", ALCEU: Revista de Comunicação, Cultura e Política, v.11 - n.16. Rio de Janeiro: PUC, Departamento de Comunicação Social, 2008.

HALL, Stuart. Identidades culturais na pós-modernidade. Rio de Janeiro: DP\&A, 1997.

NINEY, François. L'Épreuve du Réel à L'Écran, Bruxelles: Éditions de Boeck Université, 2002. 